\title{
Distinct Populations of Motor Thalamic Neurons Encode Action Initiation, Action Selection, and Movement Vigor
}

\author{
Matt Gaidica, ${ }^{1}$ Amy Hurst, ${ }^{2}$ (i) Christopher $\mathrm{Cyr}^{2}$ and ${ }^{\circ}$ Daniel K. Leventhal ${ }^{2,3,4}$ \\ ${ }^{1}$ Neuroscience Graduate Program, ${ }^{2}$ Departments of Neurology, ${ }^{3}$ Biomedical Engineering, University of Michigan, Ann Arbor, Michigan 48109, \\ and ${ }^{4}$ Department of Neurology, VA Ann Arbor Health System, Ann Arbor, Michigan 48109
}

\begin{abstract}
Motor thalamus (Mthal) comprises the ventral anterior, ventral lateral, and ventral medial thalamic nuclei in rodents. This subcortical hub receives input from the basal ganglia (BG), cerebellum, and reticular thalamus in addition to connecting reciprocally with motor cortical regions. Despite the central location of Mthal, the mechanisms by which it influences movement remain unclear. To determine its role in generating ballistic, goal-directed movement, we recorded single-unit Mthal activity as male rats performed a two-alternative forced-choice task. A large population of Mthal neurons increased their firing briefly near movement initiation and could be segregated into functional groups based on their behavioral correlates. The activity of "initiation" units was more tightly locked to instructional cues than movement onset, did not predict which direction the rat would move, and was anticorrelated with reaction time (RT). Conversely, the activity of "execution" units was more tightly locked to movement onset than instructional cues, predicted which direction the rat would move, and was anticorrelated with both RT and movement time. These results suggest that Mthal influences choice RT performance in two stages: short latency, nonspecific action initiation followed by action selection/invigoration. We discuss the implications of these results for models of motor control incorporating BG and cerebellar circuits.
\end{abstract}

Key words: basal ganglia; cerebellum; motor thalamus; movement initiation; movement vigor; Parkinson disease

Significance Statement

Motor thalamus (Mthal) is a central node linking subcortical and cortical motor circuits, though its precise role in motor control is unclear. Here, we define distinct populations of Mthal neurons that either encode movement initiation, or both action selection and movement vigor. These results have important implications for understanding how basal ganglia, cerebellar, and motor cortical signals are integrated. Such an understanding is critical to defining the pathophysiology of a range of BG- and cerebellumlinked movement disorders, as well as refining pharmacologic and neuromodulatory approaches to their treatment.

\section{Introduction}

The basal ganglia (BG) are implicated in action initiation, action selection, and movement vigor. BG neurons exhibit sharp responses as movements are initiated (Thorn et al., 2010) or suppressed (Schmidt et al., 2013), and selectively manipulating BG activity can provoke or suppress movement (Kravitz et al., 2010). Single-unit BG activity reflects the selection of lateralized alter-

Received Feb. 18, 2018; revised June 11, 2018; accepted June 13, 2018.

Author contributions: M.G. and D.K.L. wrote the first draft of the paper; M.G., A.H., C.C., and D.K.L. edited the paper; M.G. and D.K.L. designed research; M.G., A.H., and C.C. performed research; A.H. contributed unpublished reagents/analytic tools; M.G. and C.C. analyzed data; M.G. and D.K.L. wrote the paper.

This work was supported by the National Institute of Neurological Disease and Stroke (Grant K08-NS072183) and the University of Michigan. We thank Drs. William Dauer, Roger Albin, and Omar Ahmed for their thoughtful comments on this paper.

The authors declare no competing financial interests.

Correspondence should be addressed to Dr. Daniel K. Leventhal, Department of Neurology, University of Michigan, BSRB 5013, 109 Zina Pitcher Place, Ann Arbor, MI 48109-2200. E-mail: dleventh@med.umich.edu.

DOI:10.1523/JNEUROSCI.0463-18.2018

Copyright $\odot 2018$ the authors $\quad 0270-6474 / 18 / 386563-11 \$ 15.00 / 0$ natives (i.e., left or right head movements or saccades; Lauwereyns et al., 2002; Gage et al., 2010; Schmidt et al., 2013), BG manipulations bias action selection (Yamamoto et al., 2012; Leventhal et al., 2014; Hamid et al., 2016), and modeling studies suggest circuit-level mechanisms by which the BG could implement action selection (Maia and Frank, 2011). A BG role in regulating vigor, which can be conceptualized as the effort one is willing to exert in pursuit of a goal (Summerside et al., 2018), is suggested by the bradykinesia of Parkinson disease and many basic investigations (Horak and Anderson, 1984b; Mink and Thach, 1991; Bastian et al., 2003; Desmurget and Turner, 2010; Panigrahi et al., 2015; Albin and Leventhal, 2017; Thura and Cisek, 2017). For example, BG activity is correlated with decision urgency (Thura and Cisek, 2017) and movement velocity (Panigrahi et al., 2015).

The BG project to motor thalamus (Mthal), which presumably transmits action initiation, selection, and/or vigor signals to corticospinal tracts. Standard "rate" models of BG-thalamocortical interactions suggest that GABAergic BG output tonically 
suppresses Mthal, which is released to generate movement when BG output pauses (Albin et al., 1989; DeLong, 1990). Although this model makes many accurate predictions, it is incomplete (Ellens and Leventhal, 2013). Consistent with rate models, BG output lesions improve parkinsonism. However, they also treat hyperkinetic movement disorders (Cif and Hariz, 2017). Highfrequency stimulation of basal ganglia output nuclei, which likely activates efferent axons (Hashimoto et al., 2003; McIntyre et al., 2004; Boulet et al., 2006; Chiken and Nambu, 2016; Xiao et al., 2018), has clinical effects similar to lesions. Furthermore, suppressing BG output consistently slows movement, in direct opposition to rate model predictions (Horak and Anderson, 1984b; Mink and Thach, 1991; Bastian et al., 2003; Desmurget and Turner, 2010).

Corticothalamic (Yamawaki and Shepherd, 2015; Galvan et al., 2016) and cerebellothalamic (Kuramoto et al., 2011) connections also strongly influence Mthal activity (Bosch-Bouju et al., 2013; Guo et al., 2017). Cortical layer V projection neurons send collaterals to Mthal, and layer VI neurons project both directly and indirectly via reticular thalamus to Mthal (Bosch-Bouju et al., 2013). Deep cerebellar nuclear (DCN) projections form strong perisomatic "driver-like" synapses on thalamocortical neurons that are largely distinct from BG-recipient neurons (Kuramoto et al., 2011; Rovó et al., 2012). These cortical, reticular thalamic, and cerebellar inputs are potential sources of divergence between BG output and Mthal activity. The precise behavioral function(s) of Mthal, as well as the mechanisms by which they are implemented, therefore remain unclear.

To study Mthal contributions to ballistic movement, we recorded single-unit Mthal activity as rats performed a BGdependent two-alternative forced-choice task in which the pitch of an auditory cue instructs rats to move left or right (Carli et al., 1985; Dowd and Dunnett, 2005; Leventhal et al., 2012, 2014). In a stop-signal task with an identical forced-choice component, BG output decreases at movement onset, and remains low throughout movement (Schmidt et al., 2013). We therefore hypothesized that Mthal activity would be elevated throughout movement, predict which action is selected, and predict how quickly the rat completes the task. Although our results partially agreed with our predictions, we found a complex pattern of neuronal modulation suggesting that action initiation and invigoration are mediated by distinct populations of Mthal neurons.

\section{Materials and Methods}

\section{Subjects}

All animal procedures were approved by the Institutional Animal Care and Use Committee of the University of Michigan. Five adult male LongEvans rats (250-275 g, Charles River Laboratories) were housed in groups of 2-3 on a reverse light/dark cycle before electrode implantation. They were subsequently housed individually to protect the implants. Food restriction was imposed on all animals during training and testing for no more than $5 \mathrm{~d}$ in a row, with $2 \mathrm{~d}$ of free feeding in between. Upon arrival in the laboratory, rats were handled daily for 1 week to acclimate them to the laboratory environment.

\section{Behavioral task}

Operant chambers were outfitted with five illuminated nose-poke holes at the front and a food port at the back (ENV-009, Med Associates). At the beginning of each trial, one of three center nose ports was illuminated signaling the rat to poke into that port and hold for a variable delay $(0.5-$ $1 \mathrm{~s}$, pulled from a uniform distribution). The rat was then cued with a low $(1 \mathrm{kHz})$ or high $(4 \mathrm{kHz})$ pitched tone lasting $250 \mathrm{~ms}$, instructing them to poke the left or right adjacent port, respectively. Trials completed within $1 \mathrm{~s}$ of the tone in the proper direction were deemed "correct" and rewarded with a $45 \mathrm{mg}$ sucrose pellet at the food port. The intertrial interval was $15 \mathrm{~s}$. Procedural errors including initiating the trial via an unlit center port, withdrawing from the center port before the tone, or failing to poke a side port within $1 \mathrm{~s}$ were unrewarded and the house light was illuminated for the intertrial interval. "Incorrect" trials in which the rat moved to the wrong side port but met the timing criteria were unrewarded, but the house light was not illuminated. No effort was made to track head movement.

\section{Training}

Rats began training on the two-alternative forced choice task at 6 weeks of age, progressing through training levels at an individualized pace. First, all nose ports were lit and the rat was rewarded for poking any port. Next, one of the three central ports was lit and the rat was trained to poke and hold for a progressively longer delay period, with $250 \mathrm{~ms}$ of white noise signaling the reward. Finally, a low or high pitch tone (instructing left or right movement) replaced the white noise. The deadline for the rat to enter a side port after the tone was gradually reduced to $1 \mathrm{~s}$ as their performance improved. Rats were deemed ready for electrode implantation when their accuracy was $80 \%$ for 3 consecutive days and their body weight exceeded $400 \mathrm{~g}$.

\section{Implant preparation}

Implants were designed using 3D modeling software (SolidWorks) and printed with biocompatible resins (3D Systems ProJet 3500 HD Max). The electrode interface board (EIB) was designed using custom software (Advanced Circuits) and assembled by hand. The electrodes were either individual $50 \mu \mathrm{m}$ tungsten wires (California Fine Wire) or tetrodes made from $12 \mu \mathrm{m}$ nickel-chrome wire (Sandvik PX000004). The electrodes were separated using a custom matrix made with polyimide tubing (HPC Medical Products, 72113300022-039) resulting in $0.3 \mathrm{~mm}$ spacing. All electrodes were drivable via a central, mechanical platform controlled with a single drive screw. Tetrodes were gold plated twice according to vendor instructions (Neuralynx) to a final impedance $<220 \mathrm{k} \Omega$. Electrodes were submerged in mineral oil before implantation.

\section{Surgical procedures}

Rats were placed on free feed at least $24 \mathrm{~h}$ before surgery. Anesthesia was induced and maintained via isoflurane inhalation at $5 \%$ and $\sim 2 \%$ (adjusted as needed), respectively. Following induction, atropine $(0.05 \mathrm{mg} /$ $\mathrm{kg}$, Henry Schein AtroJect SA) and carprofen ( $5 \mathrm{mg} / \mathrm{kg}$, Sigma-Aldrich) were administered subcutaneously to reduce bronchial secretions and postoperative pain, respectively. Enrofloxacin $(8 \mathrm{mg} / \mathrm{kg}$, VetOne Enrosite) was administered following surgery to prevent wound infections. Body temperature was monitored and maintained via anal thermometer and abdominal heating pad $\left(37^{\circ} \mathrm{C}\right.$; Physitemp Instruments, TCAT-2LV).

Rats were secured in a stereotaxic frame using ear bars. The incision site was shaved, cleaned with ethanol and betadine, and injected with lidocaine (Henry Schein LidoJect) as a local anesthetic. A $\sim 10 \mathrm{~mm}$ anterior-to-posterior incision was made to expose the skull. The pericranium was removed and the skull cleaned with hydrogen peroxide. Bone screws (Fine Science Tools, 19010-00) were placed bilaterally along the lateral cranial ridges, and two screws placed in the posterior skull plate over the cerebellum served as ground and reference for electrophysiology. The skull was leveled and a craniotomy was performed over the recording site (Mthal; AP: $-3.1 \mathrm{~mm}$, ML: $1.2 \mathrm{~mm}$, DV: $-7.1 \mathrm{~mm}$ ). The electrodes were lowered into the brain and the gap between the implant base and skull was filled using a biocompatible silicone adhesive (World Precision Instruments, Kwik-Sil). The implant was secured using dental cement (Teets Denture Material, 525000). Rats recovered from surgery for at least 1 week before retraining on the behavioral task.

\section{Electrophysiological recordings}

Electrodes were driven down daily until at the anticipated target depth. At the end of each recording session, electrodes were driven down at least $60 \mu \mathrm{m}$ so that new units were identified in each session. Wideband signals $(0.1 \mathrm{~Hz}$ to $10 \mathrm{kHz})$ from the EIB were transmitted through a digital headstage, motorized commutator, preamplifier, data processor, and streamed to storage (Tucker-David Technologies: ZD64, AC32, PZ4, RZ2, RS4). Data were filtered in MATLAB (RRID:SCR_001622; $244 \mathrm{~Hz}$ to $6.10 \mathrm{kHz}$ ) and manually sorted into single units (Offline Sorter, 

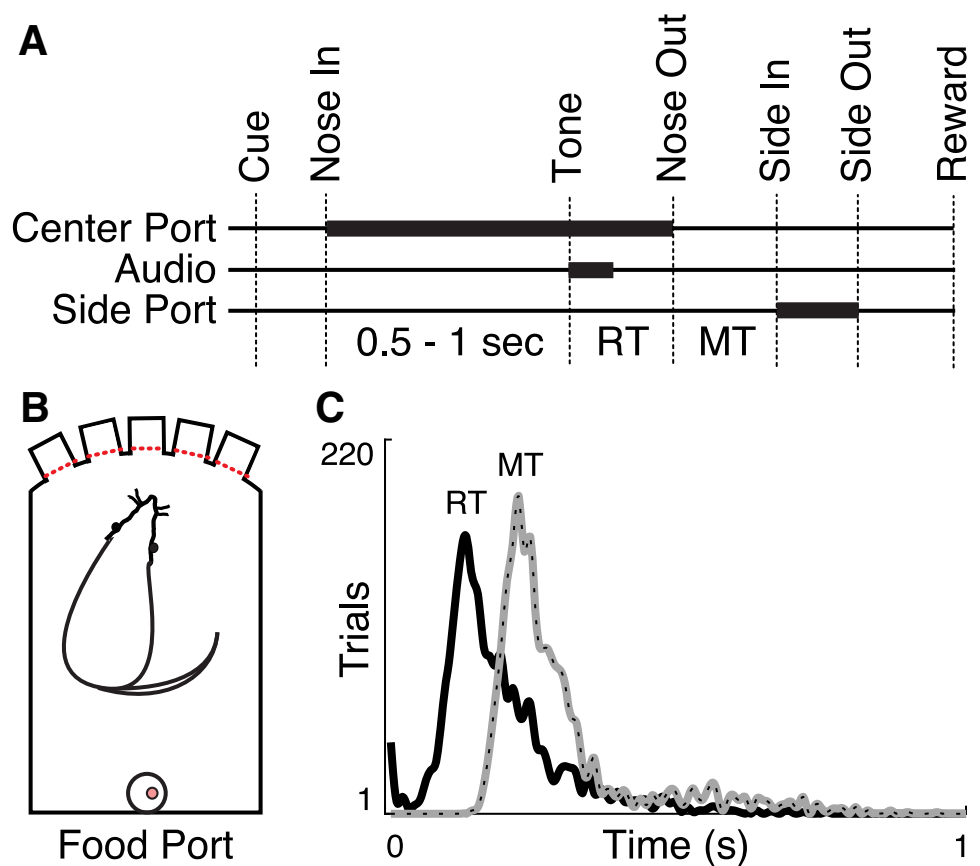

C

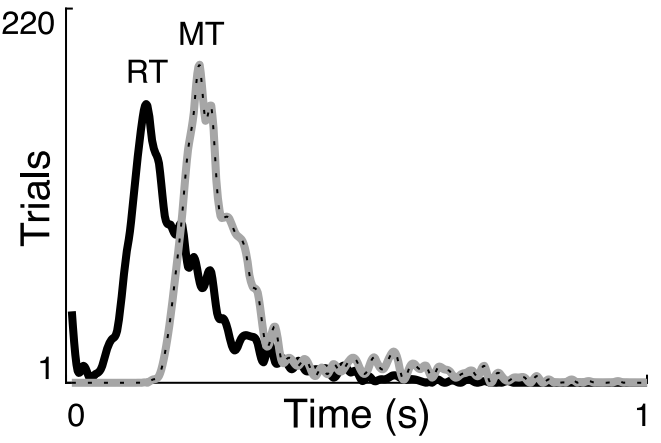

Figure 1. Behavioral task. $\boldsymbol{A}$, Trials began by illuminating one of the three center ports in a five-port behavior chamber (Cue). The rat poked and held its nose in the lit port (Nose In) for a variable interval ( $0.5-1 \mathrm{~s}$, pulled from a uniform distribution) until a 1 or $4 \mathrm{kHz}$ auditory cue played (Tone) instructing the rat to move one port to the left or right, respectively. Nose Out, Side In, and Side Out indicate when the rat withdrew from the central port, poked the adjacent port, and withdrew from the adjacent port, respectively. "Reward" indicates the time of reward pellet retrieval. $\boldsymbol{B}$, schematic diagram of the operant chamber. $\boldsymbol{C}$, RT and MT distributions ( $10 \mathrm{~ms}$ bins, 5 -point smoothed) for all trials.

RRID:SCR_000012). Potential duplicate units (i.e., the same unit recorded in multiple sessions) were identified by comparing the spike waveforms, unit autocorrelograms, cross-correlograms, and firing rates between sessions ("Tracking neurons over multiple days", MATLAB Central ID 30113; Fraser and Schwartz, 2012). Fifty-three potential duplicate units were excluded from subsequent analysis. The behavior chambers were controlled by LabVIEW software that stored behavioral data and a video of each session. Digital pulses indicating behavioral events (e.g., cues, nose pokes) and video frames were transmitted from the behavioral control software to the electrophysiology rig to synchronize behavior and electrophysiology.

\section{Data analysis}

Classification of single-unit event responsiveness. Peri-event time histograms (PETHs) of $Z$-scored firing rates were used to determine the taskrelated modulation of single-unit activity. We used a $\pm 1 \mathrm{~s}$ window with 20 ms bins smoothed by a three-point moving average for all PETH analyses. The mean and SD used in calculating each $Z$-score was obtained from the $2 \mathrm{~s}$ period before the "Cue" event (Fig. 1A). We chose this epoch because animals were not engaged in the task, and by observation, were unlikely to be exploring the cage or grooming. Primary unit classes were determined by finding the event for which the absolute value of a unit's $Z$-score was maximal and exceeded 1 within $\pm 200 \mathrm{~ms}$ around the event. Secondary unit classes were determined by finding the next highest absolute peri-event $Z$-score with the following restrictions. Secondary events could not be immediately before or after a unit's primary event. Second, to ensure at least a moderate degree of modulation, the absolute value of the secondary $Z$-score had to either exceed 1 or be greater than one-half of the unit's maximum primary $Z$-score. Units whose activity was not modulated strongly enough to be assigned to an event were classified as nonresponsive (NR). Only primary task-modulated units could be assigned secondary event classifications (i.e., the secondary classification of primary NR units could only be NR).

Identification of directionally selective units. Directional coding on a per-unit basis was assessed by creating \pm 1 s PETHs independently for contralateral and ipsilateral trials. The ipsilateral PETHs were subtracted from the contralateral PETHs, resulting in a time series representing the firing rate difference between the two trial types. Statistical comparisons between PETHs were performed with a shuffle test (Schmidt et al., 2013). We randomly reassigned trial type labels 1000 times to calculate surrogate PETH differences. $p$ Values were determined as the fraction of surrogate PETH differences greater (or less) than the actual PETH difference. In each time bin, a unit was counted as directionally selective if $p<0.01$. We labeled any unit that showed sustained selectivity for at least $40 \mathrm{~ms}$ around the Nose Out event ( -200 to $400 \mathrm{~ms}$ ) "directionally selective" and exclusively classified them as contralaterally or ipsilaterally selective. If a unit was selective for both directions at different times, we classified it based on the earliest time when our selection criteria were met. To quantify the magnitude of a unit's directional selectivity, we summed the difference between the ipsilateral and contralateral PETHs for bins in which this difference was significant ( -200 to $400 \mathrm{~ms}$ around Nose Out; see Fig. 4C). Directional selectivity for incorrect trials was assessed using the same criteria but was limited by the small number of such trials. Directional selectivity at the Side Out event was determined using the same criteria except trials were sorted by the direction the rat moved to the food port based on manual video review.

Correlations between single-unit activity, $R T$, and MT. Visual inspection of our RT distribution revealed distinct early (express), "main", and late components (Figs. $1 C, 5 A, B)$. We empirically identified the main RT distribution (Noorani and Carpenter, 2011) as between 50 and $350 \mathrm{~ms}$. Similarly, the movement time (MT) distribution comprised two distinct components (there is no express component of the MT distribution). Empirically, the main MT distribution was identified between 0 and $400 \mathrm{~ms}$. Consistent with results from similar tasks, our ordinary trials (i.e., those with RT and MT within the main distributions) comprised $\sim 90 \%$ of all trials.

The main RT and MT distributions for all trials were divided into 10 quantiles, and average PETHs were generated for directionally and nondirectionally selective units. We identified two epochs around the Nose Out event where single-unit $Z$-scores varied systematically with RT or MT (see Fig. 5) for further analysis. The minimum $Z$-score for each quantile was extracted from between -0.7 and $-0.2 \mathrm{~s}$ with respect to the Nose Out event (see Fig. 5, black arrows), and the maximum peri-event $Z$-score was extracted from between -0.2 and $0.3 \mathrm{~s}$ (see Fig. 5 , red arrows). These values were then regressed against RT and MT (see Fig. 5).

All subject data were stored in a MySQL database, analyzed using MATLAB, and versioned using Git.

\section{Anatomic localization of recording sites}

Animals were deeply anesthetized and electrolytic lesions were made by passing 15-30 $\mu \mathrm{A}$ between each electrode and the ground wire. Animals were killed in accordance with AVMA guidelines by cardiac perfusion with 10\% paraformaldehyde (PFA; Sigma-Aldrich, P6148). The implant was removed, cleaned with ethanol and stored. The brain was sequentially stored in the following solutions: $10 \%$ PFA, $20 \%$ sucrose/PBS, $30 \%$ sucrose/PBS, 50\% OCT, 100\% OCT (PBS-PBS,OCT, Fisher Healthcare Tissue-Plus Optimal Cutting Temperature Compound). Brain slices were taken on a cryostat (Leica CM3050 S) at $30 \mu \mathrm{m}$ intervals, stained using cresyl violet acetate to highlight Nissl substance, and digitally imaged under bright-field illumination. Electrolytic lesions were identified from images in Adobe Photoshop (RRID:SCR_014199) and electrode tracks were followed to the dorsal entry point. The implant (with electrodes intact) was imaged and analyzed to create a three-dimensional 


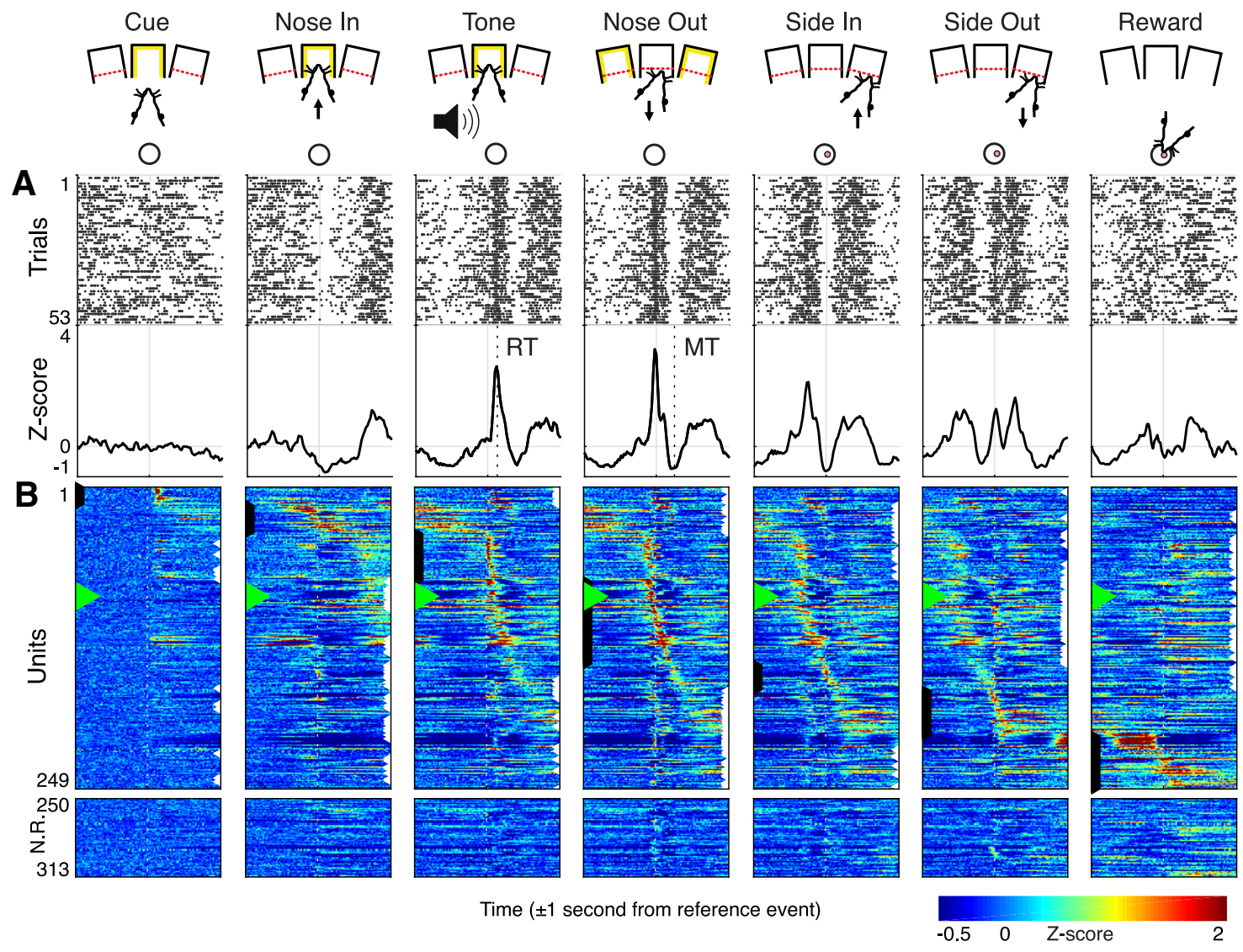

Figure 2. Single-unit Mthal activity during task performance. $A$, Single-unit raster (top) and PETHs (bottom) of a Nose Out responsive unit. Vertical dashed lines indicate the median RT (132 ms) and MT (249 ms) in this session. $\boldsymbol{B}$, PETHs for all units sorted by their primary unit class and the timing of their maximal Z-score. Black and white arrows along the column edges indicate the primary and secondary unit classification, respectively. Green triangles in $\boldsymbol{B}$ indicate the unit from $\boldsymbol{A}$.

electrode map to correlate with the location of electrolytic lesions in the histology images. We morphed the histology images to match standard rat brain maps (Paxinos and Watson, 2007).

\section{Statistics}

Directional coding was determined using a shuffle test with 1000 random permutations (MATLAB randperm) of trial labels (i.e., contraversive vs ipsiversive movement). We used a binomial inverse cumulative distribution (MATLAB binoinv) to determine the fraction of units expected to show directional coding by chance (Schmidt et al., 2013; $p<0.01$ ). Statistical significance between fractions of units belonging to a particular class or group was determined using the $\chi^{2}$ test. RT and MT regressions were fit using a linear polynomial curve to determine $R^{2}$ with $p$ values computed using Pearson's linear correlation coefficient (MATLAB fit and corr, respectively). Each fit was reported with $95 \%$ confidence intervals (MATLAB polyconf). Electrophysiological characteristics were plotted using MATLAB boxplot. Unless stated otherwise, numbers are reported as the mean $\pm \mathrm{SD}$.

\section{Results}

\section{Motor thalamic modulation at movement onset}

We trained rats on a two-alternative forced-choice task that strongly modulates BG activity (Schmidt et al., 2013) and depends on intact BG function (Leventhal et al., 2014). Rats were cued to poke and hold in one of the three center ports in a fiveport behavior chamber for a variable interval, then directed one port to the left or right by the pitch of an instructional cue (Fig. $1 A, B)$. Choice accuracy ( $77 \pm 17 \%$ during recording sessions), reaction time (RT) distributions, and MT distributions were consistent with previous results (Schmidt et al., 2013; Leventhal et al.,
2014; Fig. 1C). Once well trained, rats were implanted with microelectrodes targeting Mthal.

To determine the behavioral correlates of Mthal activity, PETHs of single-unit $Z$-scored firing rates were constructed and collapsed into a peri-event heatmap (Fig. 2). The two nonadjacent events to which each unit responded most strongly were designated the "primary" (strongest response) and "secondary" (second strongest response) events for that unit. Units that failed to achieve an absolute Z-score of at least 1 were classified as NR (64/313; Figs. 2B, 3A). Most task-responsive units (96\%) were classified based on a positive $Z$-score (i.e., a peri-event increase in firing rate). Notably, $57 \%$ of all units were either primary or secondary Tone or Nose Out units, meaning that they were highly modulated when the rat decided which direction to move and quickly initiated that movement. These firing rate modulations were brief, returning to baseline or lower before the lateral movement completed ("Side In"). This result is inconsistent with a strict rate model, and suggests that Mthal may be required to initiate, but not sustain, movement.

Although Tone and Nose Out units were modulated closely in time, they were preferentially time-locked to qualitatively different events. We further evaluated whether Tone and Nose Out units might represent functionally distinct populations by examining the distribution of their secondary classes (Figs. $2 B, 3 B$ ). The secondary events of primary Tone units were fairly evenly distributed among other task events. However, primary Nose Out units were more likely than primary Tone units to be second- 


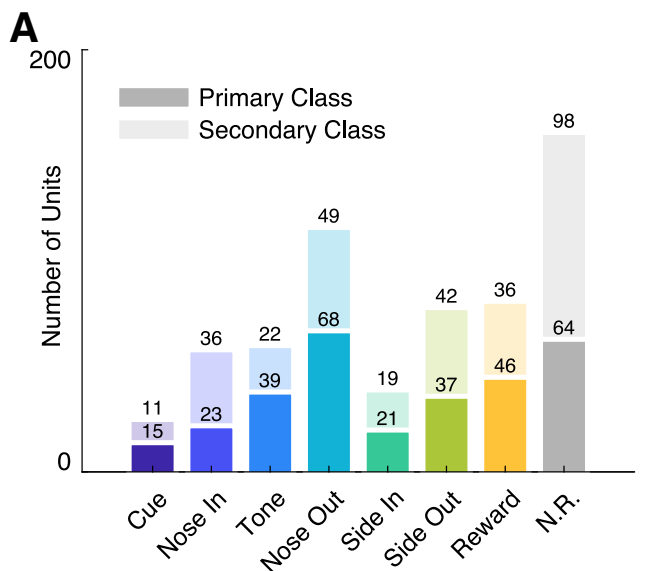

B
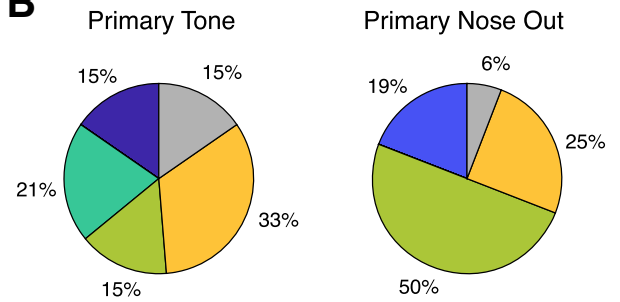

Figure 3. Numbers of units with activity time-locked to behavioral events. $A$, Distribution of primary (bottom, dark bars) and secondary (top, light bars) unit classes. Numbers above each bar indicate the number of units preferentially locked to each event. $\boldsymbol{B}$, Distributions of secondary events for primary Tone (left) and Nose Out (right) units. Tone units show an approximately equal preference for firing at other events while Nose Out units are highly modulated at Side Out.

ary Side Out units, when the rat is changing direction and moving quickly $\left(p=1.9 \times 10^{-4}, \chi^{2}\right.$ goodness of fit test comparing proportions of secondary Side Out units). This suggests that "Nose Out" units may have a general role in generating movement, whereas Tone unit activity is specifically linked to external cues.

\section{Action selection in the motor thalamus}

Activity in multiple BG nuclei is correlated with action selection (i.e., the choice to move left or right) in similar nose-poke tasks (Gage et al., 2010; Schmidt et al., 2013), and unilateral inactivation of BG nuclei or striatal dopaminergic manipulations bias action selection (Carli et al., 1985; Baunez et al., 2001; Dowd and Dunnett, 2005; Leventhal et al., 2014). We therefore examined whether action selection signals were transmitted through Mthal.

To determine whether Mthal encodes movement direction, we subtracted mean peri-event $Z$-scores for ipsilateral movements from those for contralateral movements (Fig. 4), and determined the fraction of units at each moment whose firing rates correlated with movement direction (Fig. 4B; Schmidt et al., 2013). Directional coding increased earlier for contraversive than ipsiversive movements; contraversive selectivity peaked $140 \mathrm{~ms}$ after Nose Out, whereas ipsiversive selectivity peaked $200 \mathrm{~ms}$ after Nose Out. The maximum fraction of units coding movement direction within any time bin was $24 \%$, also occurring 200 ms after Nose Out. Thus, Mthal strongly encodes movement direction, but not until just before movement initiation, suggesting that Mthal drives lateralized movement.

We next examined the functional characteristics of individual directionally selective units, defined by direction-specific activity for at least two consecutive time bins $(40 \mathrm{~ms})$ around the Nose Out event (Fig. 4C). Mthal activity tended to correlate with the direction moved rather than the direction cued on the infrequent occasions that rats moved the wrong direction (14/21 directionally selective units with $>5$ incorrect trials exhibited movementcorrelated rather than instruction-correlated activity), suggesting that directionally-selective Mthal activity is linked to movement and not auditory perception. This is further supported by the observation that Nose Out units were more likely to be directionally selective than Tone units (39\% of Nose Out units vs $18 \%$ of Tone units were directionally selective; Fig. $4 D ; p=1.6 \times 10^{-8}$ ). However, individual units frequently encoded opposite directions at the Nose- and Side-Out events (57\% of units with concordant directional selectivity; $p=0.17$ against the null hypothesis of $50 \%$ concordance). The median duration of single-unit directional selectivity was $140 \mathrm{~ms}$ compared with the median MT of $258 \mathrm{~ms}$. Therefore, Tone units may contribute to nonspecific aspects of movement initiation, after which Nose Out units provide a brief signal to drive movement to the left or right.

\section{Motor thalamus encodes movement vigor}

The BG are believed to play a critical role in appropriately invigorating or scaling movement (Desmurget and Turner, 2010; Dudman and Krakauer, 2016; Yttri and Dudman, 2016; Thura and Cisek, 2017). Movement vigor can be conceptualized as the metabolic cost of performing an action (Niv et al., 2007; Summerside et al., 2018). In the context of this forced-choice task, this metabolic cost should be related to how quickly rats initiate (RT) and execute (MT) their chosen action (Niv et al., 2007).

If the directional selectivity we observed in Mthal results from selective movement invigoration in one direction, then the activity of directionally selective, but not nondirectionally selective, units should predict RT and MT. To investigate this possibility, we superimposed RT and MT on single trial rasters separately for directionally and nondirectionally selective units around the Nose Out event (Fig. 5). We then asked whether there was a relationship between trial-by-trial activity and RT/MT.

The RT distribution was divided into three regions (Noorani and Carpenter, 2011). The first is a set of very short RTs ( $<50 \mathrm{~ms}$; Fig. $5 A, B$, gray overlays at the top of the rasters) that likely represents "express" movements in which the rat anticipated, rather than responded to, the instructional cue (Carpenter and Williams, 1995). At very long RTs (>350 ms; Fig. $5 A, B$, gray overlays at the bottom of the rasters), motor thalamic activity no longer was modulated by the task. We therefore focused on the intermediate "main" RT distribution (89\% of all trials; Fig. 5 A, B, cyanviolet overlay). Nondirectionally selective Tone and Nose Out units showed a single firing peak just before the Nose Out event, consistent with the fact that most Tone units were not directionally selective. To our surprise, however, the activity of these units was strongly related to RT (Fig. 5A). Their firing rates at Nose Out were anti-correlated with RT $\left(R^{2}=0.75, p=1.1 \times 10^{-3}\right)$. Furthermore, there was a decrease in firing several hundred milliseconds before Nose Out whose depth was also related to RT $\left(R^{2}=\right.$ $\left.0.78, p=6.8 \times 10^{-4}\right)$. Finally, for very short and long RT, the approximately linear relationship between RT and neural activity disappeared.

We performed a similar analysis on the relationship between nondirectionally selective unit activity and MT (Fig. 5C). As was the case for RT, units were not strongly modulated around the Nose Out event for very long MT ( $>\sim 400 \mathrm{~ms})$. Because there is no express component of MT distributions, we analyzed correlations between motor thalamic activity and MTs between 0 and $400 \mathrm{~ms}$ ( $88 \%$ of all trials). Unlike for RT, there was no relationship between the firing rate of nondirectionally selective units 

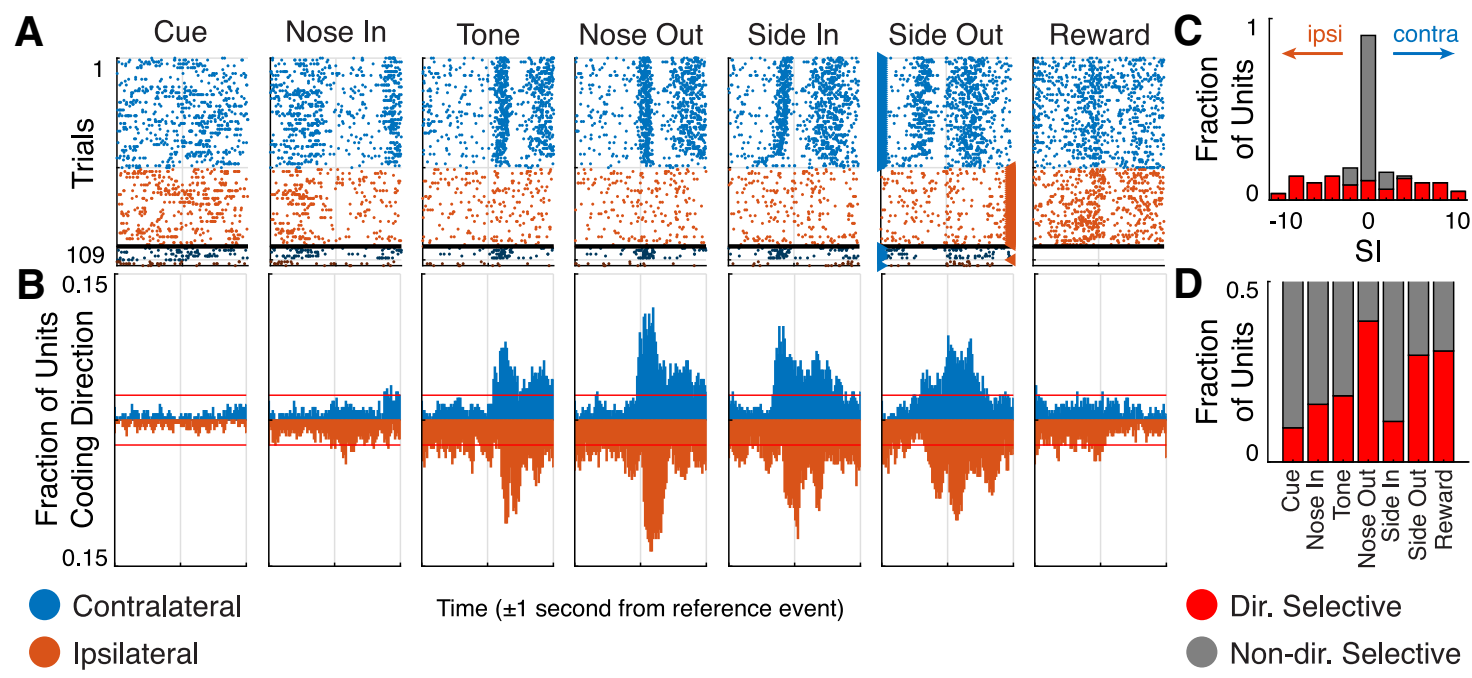

Figure 4. Directional selectivity of Mthal units. $\boldsymbol{A}$, Peri-event rasters from a single unit sensitive to movement direction. Trials are segregated into four groups from top to bottom: cued contralateral, moved contralateral; cued ipsilateral, moved ipsilateral; cued ipsilateral, moved contralateral; and cued contralateral, moved ipsilateral. Trials are sorted by MT within each group. Markers on either side of the Side Out event indicate the direction the rat turned to retrieve the sugar pellet. $\boldsymbol{B}$, Fraction of units showing directional selectivity on correct trials. Counts above the horizontal axis indicate increased firing for contralateral movement; counts below the axis indicate increased firing for ipsilateral movements. Horizontal red lines indicate a chance level of directional selectivity. C, Histograms of selectivity indices (Sls) for directionally (red bars) and nondirectionally selective (gray bars) units. D, Fraction of units that exhibit directional selectivity (red bars) at the Nose Out event according to their event responsiveness.

and MT in the pre- or peri-Nose Out periods $\left(R^{2}=0.0048, p=\right.$ 0.85 and $R^{2}=0.12, p=0.33$, respectively).

The activity of directionally selective units included an early peak before the Nose Out event similar to nondirectionally selective units, and also a slightly later peak (Fig. 5B). As for nondirectionally selective units, activity around the Nose Out event was anticorrelated with RT $\left(R^{2}=0.85, p=1.5 \times 10^{-4}\right)$, and there was an early depression in their activity that predicted RT $\left(R^{2}=\right.$ $0.54, p=0.016$ ). Critically, and in contrast to nondirectionally selective units, the activity of directionally selective units strongly predicted MT in the peri-Nose Out period $\left(R^{2}=0.94, p=4.4 \times\right.$ $10^{-6}$; Fig. $\left.5 D\right)$. There was no relationship between firing rates before Nose Out and MT for directionally selective units $\left(R^{2}=\right.$ $0.0074, p=0.81$ ).

In summary, we identified two groups of Mthal neurons whose firing patterns were strongly related to movement initiation and action selection/execution. The activity of one group tended to be more tightly locked to the instruction cue, did not predict movement direction, and predicted RT. The activity of the second group was more tightly locked to movement initiation, predicted movement direction, and predicted both RT and MT. These results suggest that the apparent directional selectivity of Mthal neurons reflects a "vigor" signal transmitted through this central motor hub. Furthermore, subpopulations of motor thalamic neurons subserve related but distinct roles in initiating and executing motor plans.

\section{Single-unit anatomy and physiology}

The BG and cerebellar-recipient thalamus are largely segregated in the rat, with ventral-anterior regions of Mthal more likely to receive $B G$ afferents and dorsal-posterior regions more likely to receive cerebellar afferents (Deniau et al., 1992; Kuramoto et al., 2011). We therefore asked whether units with different behavioral correlates (i.e., event-responsiveness or directional selectivity) tended to aggregate in Mthal subregions. There was no apparent anatomic clustering of units based on their directional selectivity (Fig. 6A) or primary event class (Fig. $6 \mathrm{~B}$ ), though it is difficult to determine recording sites precisely since electrodes were moved between recording sessions. Furthermore, directionally and nondirectionally selective units were indistinguishable by conventional physiologic measures (Fig. $6 \mathrm{C}$ ). This is consistent with previous reports that extracellular recordings are homogeneous across Mthal subregions, at least when animals are not engaged in a specific task. (Anderson and Turner, 1991; Nakamura et al., 2014).

\section{Discussion}

We found functionally distinct neuronal populations in Mthal whose activity changes briefly around movement onset. Units that did not encode movement direction were more likely to respond to the instruction/imperative cue, and predicted RT ("initiation" units). Conversely, units whose activity correlated with movement direction predicted RT and MT, and were more likely to respond at movement onset ("execution" units). These results suggest that RT and MT may not be interchangeable measures of vigor, and are regulated via distinct subcortical mechanisms. Furthermore, Mthal influences choice RT performance in two stages: short latency, nonspecific action initiation followed by action selection/invigoration.

Similar to our data (Fig. 2) in simple RT tasks with one response option, Mthal activity changes are distributed from just before to just after movement onset (Macpherson et al., 1980; Anderson and Turner, 1991; Nambu et al., 1991; van Donkelaar et al., 1999; Tanaka, 2007). Although the duration of firing rate changes was not systematically examined in these studies, several units exhibited brief increases that returned to baseline before movement completion (compare Fig. 2 to Anderson and Turner, 1991, their Fig. 7B). In a choice RT task, Mthal units were modulated around movement onset, and elevated firing did not persist through movement completion (Butler et al., 1992; Forlano et al., 1993). In contrast, rat Mthal activity was briefly modulated near the grasping phase of a skilled reaching task (Bosch-Bouju et al., 2014). However, because reaches were spontaneous, it is difficult to determine precisely how Mthal activity was modulated at reach initiation. Collectively, these data suggest that phasic 
A
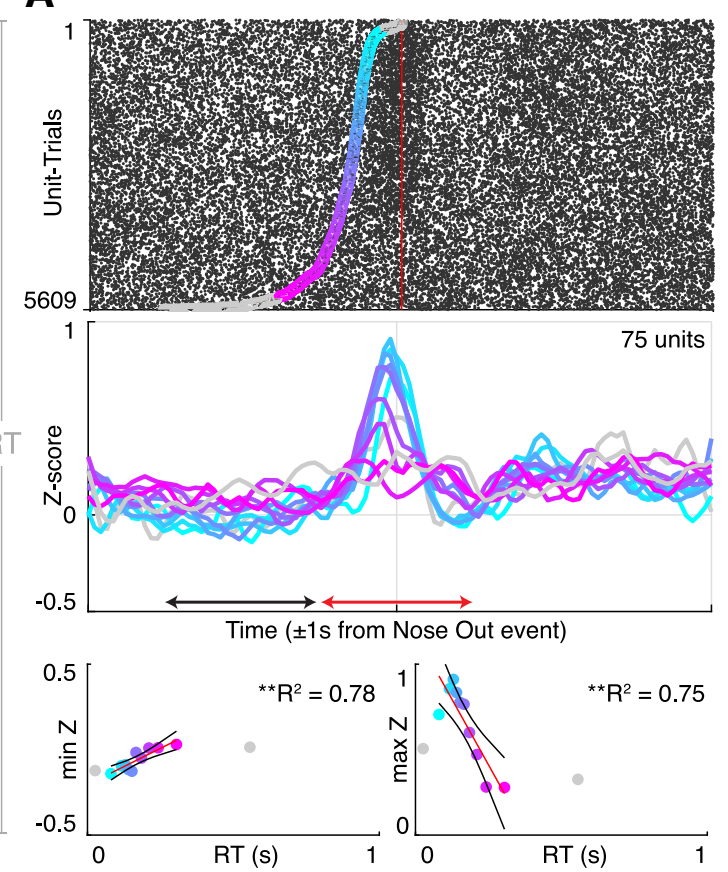

C
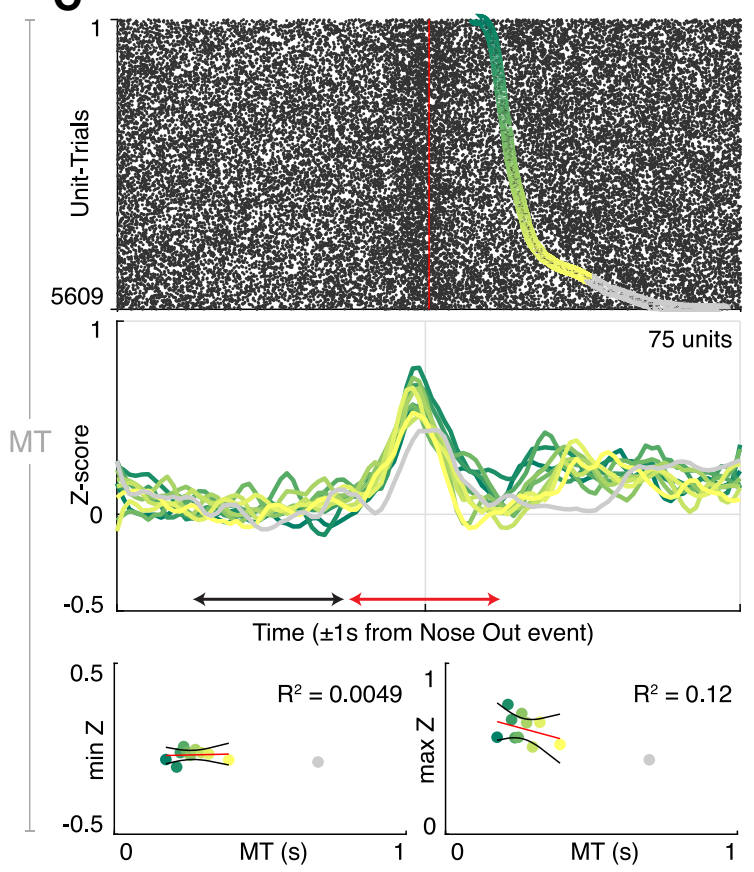

B
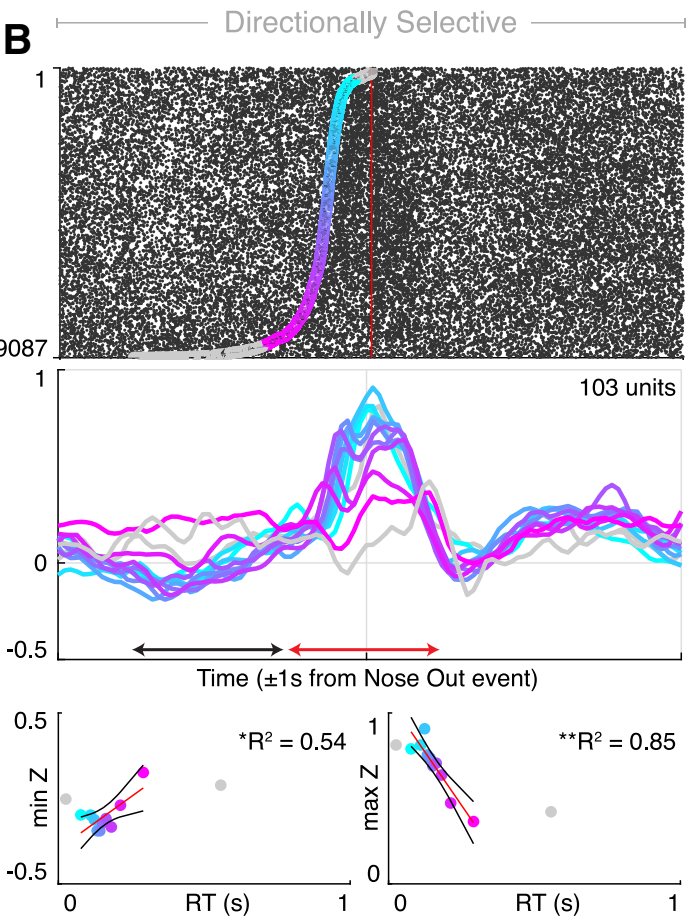

D
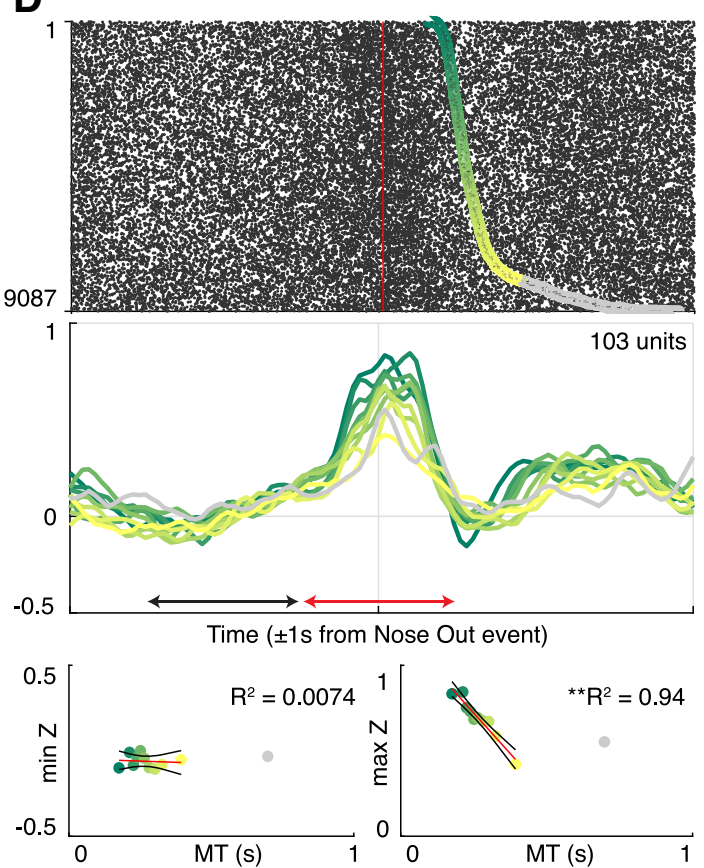

Figure 5. Relationships between single-unit activity, RT, and MT. Top, Single trial rasters for each nondirectionally selective $(\boldsymbol{A}, \boldsymbol{C})$ or directionally selective $(\boldsymbol{B}, \boldsymbol{D})$ unit sorted by RT $(\boldsymbol{A}, \boldsymbol{B})$ or MT $(C, D)$. Cyan-violet overlays indicate the Tone event for the main RT distribution; green-yellow overlays indicate the Side In event for the main MT distribution. Gray overlays indicate short (express) RT or long RT/MT. Middle, Mean peri-event Z-scores for each RT $(\boldsymbol{A}, \boldsymbol{B})$ or MT $(\boldsymbol{C}, \boldsymbol{D})$ decile. Colored traces correspond to shading in the raster above. Bottom left, Linear regressions of minimum Z-score in the pre-Nose Out period (black arrow on the PETHs above) against RT $(\boldsymbol{A}, \boldsymbol{B})$ or MT $(\boldsymbol{C}, \boldsymbol{D})$. Bottom right, Linear regressions of maximum Z-score in the peri-Nose Out period (red arrow on the PETHs above) against $\mathrm{RT}(\boldsymbol{A}, \boldsymbol{B})$ or $\mathrm{MT}(\boldsymbol{C}, \boldsymbol{D}) .{ }^{*} p<0.05,{ }^{* *} p<0.01$.

changes in Mthal activity occur at movement transitions, whether from rest to reaching or reaching to grasping.

A pulse of Mthal activity could propel motor cortex from a preparatory state into movement execution. Upon imperative cue presentation, population-level motor cortical activity evolves dynamically depending on the specific action being executed (Churchland et al., 2012). Similar to Mthal initiation units, a component of this activity is invariant across potential actions, predicts movement timing but not velocity, and precedes actionspecific cortical activity (Kaufman et al., 2016). We speculate that initiation units trigger action-invariant components of movementrelated cortical dynamics. Execution units then invigorate actionspecific cortical population-level activity (Churchland et al., 2012). In both cases, Mthal modulations are early and brief relative to movement duration. In fact, many Tone and Nose Out units transiently decrease firing below baseline rates immediately after their event-related firing 
A

A Lateral $1.4 \mathrm{~mm}$

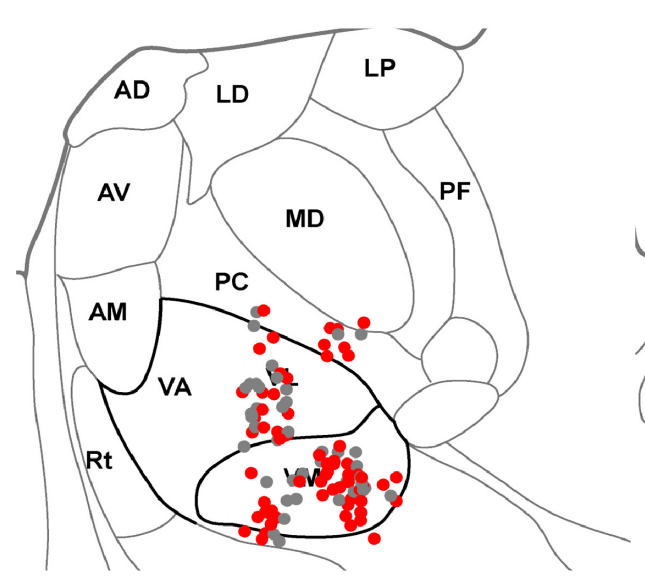

Lateral $1.9 \mathrm{~mm}$

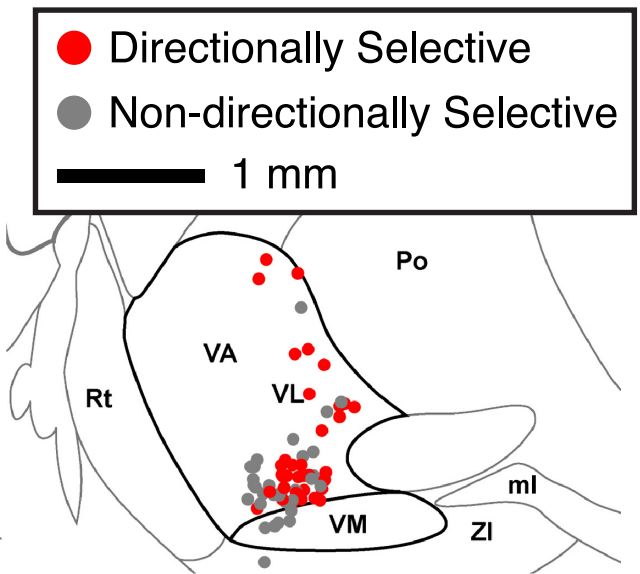

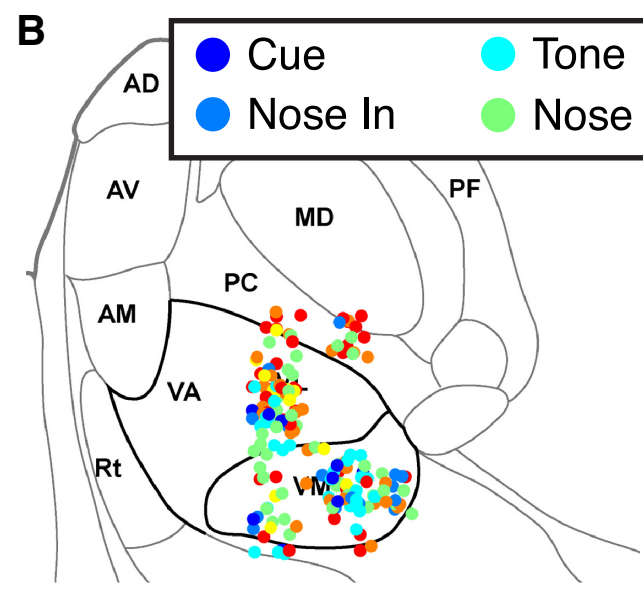

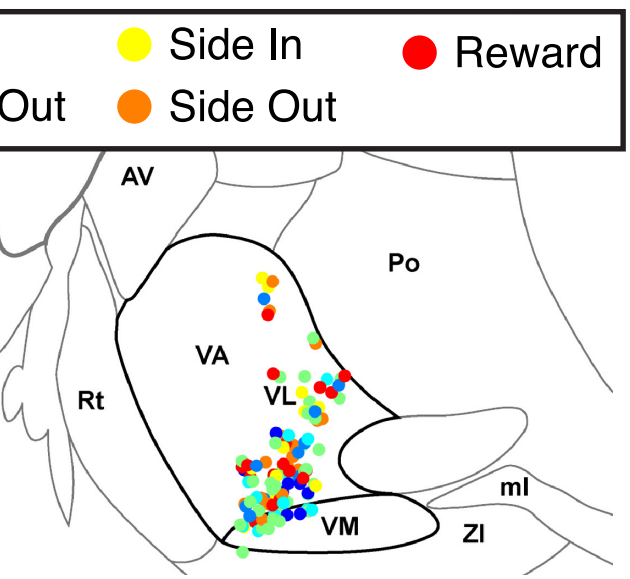

C
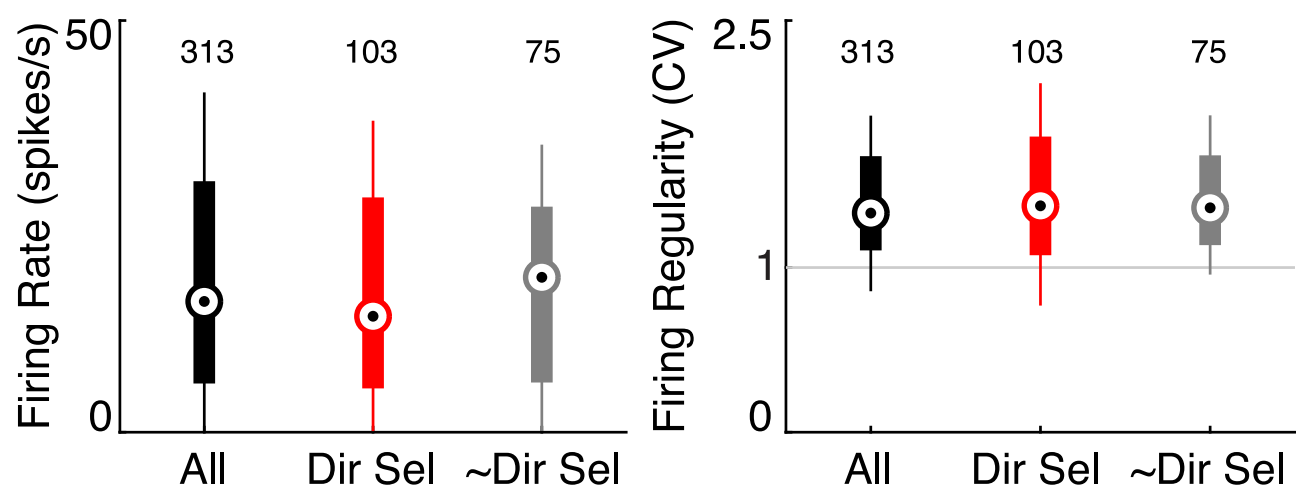

All Dir Sel $\sim$ Dir Sel

Figure 6. Anatomical and electrophysiological characteristics of Mthal units. A, Location of directionally (red) and nondirectionally selective (gray) units superimposed on sagittal rat brain atlas images (Paxinos and Watson, 2007). Mthal nuclei [ventral anterior (VA), ventral lateral (VL), ventromedial (VM)] are enclosed within bold lines. AD, Anterodorsal thalamus; AM, anteromedial thalamus; $\mathrm{AV}$, anteroventral thalamus; LD, laterodorsal thalamus; $\mathrm{LP}$, lateral posterior thalamus; $\mathrm{MD}$, mediodorsal thalamus; ml, medial lemniscus; $\mathrm{PC}$, paracentral thalamus; $\mathrm{PF}$, parafascicular thalamus; Po, posterior thalamic nuclear group; Rt, reticular thalamus; Zl, zona incerta. $\boldsymbol{B}$, Anatomical characterization of Mthal units based on event responsiveness. There was no clear anatomic segregation of units based on directional selectivity or event-responsiveness. C, Left, Median firing rates of all, directionally selective (Dir Sel), and nondirectionally selective ( Dir Sel) units. Right, Median coefficient of variation (CV) for the same units. Thick lines indicate the 10th to 90th percentiles. The whiskers extend to the most extreme data points not considered outliers.

rate increase (Figs. 2B, 5; Tanaka, 2007; Bosch-Bouju et al., 2014). These observations are consistent with the idea that cortical dynamics evolve in a predetermined manner depending on their initial state (Churchland et al., 2010). This is analogous to pushing a pendulum, which behaves as a harmonic oscillator: its kinematics are uniquely determined by its initial state and the force with which it is pushed (unless acted upon again; Dudman and Krakauer, 2016; Yttri and Dudman, 2018). This hypothesis should be testable by manipulating the timing of Mthal activation with respect to the onset of a ballistic movement. Such a mechanism may be important for preplanned ballistic movements, as opposed to slower movements that require continuous adjustment (Tanaka, 2005).

The idea that precisely-timed pulses of Mthal activity regulate movement vigor may explain the apparent paradox that BG output lesions and high-frequency stimulation slow movement in healthy subjects, speed movement in parkinsonian subjects (Bastian et al., 2003), and improve dyskinesias (Marsden and Obeso, 
1994; Ellens and Leventhal, 2013). High-frequency, bursty BG output in Parkinson disease (Ellens and Leventhal, 2013; Galvan et al., 2015) could force persistent Mthal bursting (Zirh et al., 1998; Magnin et al., 2000; Guehl et al., 2003; Molnar et al., 2005; Pessiglione et al., 2005; Rubin et al., 2012; Kim et al., 2017) and prevent the natural evolution of cortical dynamics. Eliminating aberrant BG output would restore baseline corticothalamic function, but not allow vigor modulation by BG-thalamocortical circuits. Critically, tonic BG output imposed by high-frequency stimulation would have a similar effect.

It remains unclear how distinct subcortical afferents influence Mthal activity and behavior. One possibility is that initiation and execution units represent cerebellar- and BG-recipient thalamocortical neurons, respectively. Suppressing DCN activity prolongs RT (Meyer-Lohmann et al., 1977; Trouche and Beaubaton, 1980). Transient increases in DCN activity precede and are timelocked to saccades (Ohmae et al., 2017) or limb movements in a simple RT task (Thach, 1975). Furthermore, Purkinje neuron inhibition releases DCN from tonic inhibition and initiates movement (Heiney et al., 2014). Finally, after pairing Purkinje neuron inhibition with an auditory cue, the auditory stimulus itself is sufficient to increase DCN activity and initiate movement (Lee et al., 2015). Cerebellum-dependent action initiation could be driven via Mthal, though the $\mathrm{DCN}$ also project to the superior colliculus and red nucleus (Teune et al., 2000).

Conversely, the BG are implicated in action selection (Maia and Frank, 2011; Redgrave et al., 2011; Jin et al., 2014) and regulating movement vigor (Panigrahi et al., 2015; Dudman and Krakauer, 2016). In simple RT tasks, BG output lesions/inactivations slow MT, but not RT (Horak and Anderson, 1984a; Mink and Thach, 1991; Desmurget and Turner, 2010). Furthermore, Parkinson disease patients react and move slower during choice RT tasks than healthy controls (Pullman et al., 1988). In tasks similar to the one used here, striatal dopamine depletion (Carli et al., 1985; Dowd and Dunnett, 2005 Leventhal et al., 2014), striatal inactivation (Leventhal et al., 2014), or subthalamic lesions (Baunez et al., 2001) impair action selection and prolong RT and MT. Single units in striatum, globus pallidus, the subthalamic nucleus, and $\mathrm{SNr}$ encode movement direction in this task (Gage et al., 2010; Schmidt et al., 2013). Thus, BG-recipient Mthal is a candidate to convey vigor and action-specific signals from the BG into corticospinal tracts. Alternatively, initiation and execution units may be distributed across Mthal subregions, with BG- and cerebellum-derived signals mixing through recurrent corticothalamic loops (Bosch-Bouju et al., 2013), disynaptic connections between the BG and cerebellum (Bostan et al., 2010; Chen et al., 2014), or sparse cerebellar projections to BG-recipient thalamus (Deniau et al., 1992; Kuramoto et al., 2011). The latter projections could explain why execution units predict RT as well as MT.

The correlation between depressed hold period Mthal activity and RT (Fig. $5 A, B$ ) suggests an attentional mechanism to anticipate the cue. Thalamocortical neurons express $\mathrm{T}$-type $\mathrm{Ca}^{2+}$ channels that de-inactivate during hyperpolarization, increasing excitability (Kim et al., 2017). While extracellular recordings cannot determine whether firing rate depressions correspond to membrane hyperpolarization, the correlation between the depth of the hold period depression and the height of the peri-Nose Out peak implies a rebound phenomenon. Mthal hyperpolarization could be caused by enhanced BG output, though SNr hold period activity is not elevated in a similar task (Schmidt et al., 2013, their Fig. S8). Alternatively, decreased Mthal activity could reflect increased reticular thalamic inhibition (Guo et al., 2017) or decreased cortical excitation (Galvan et al., 2016; Guo et al., 2017).
However, it is also possible that network mechanisms account for the correlations between depressed pre-tone firing rate, periNose Out peak firing, and behavior.

Premotor corticothalamic loops can maintain selected actions in working memory when instructive cues precede imperative cues, and disrupting corticothalamic activity reduces task performance to chance (Guo et al., 2017). In our task, the instructive and imperative cues arrive simultaneously, and nonspecific RTcorrelated action initiation signals precede direction-specific MT-correlated signals (compare Figs. 5A, D). These results suggest that movement may be initiated by subcortical circuits, but action selection (at least in this task) requires corticothalamic communication. The selected action could be maintained in working memory or used immediately to influence ongoing movement (Fig. 5D). Correlations between BG-recipient Mthal activity and action selection also suggest that action-specific execution units are part of BG-Mthal-prefrontal circuits.

Most models of choice RT performance suggest that action preparation and movement initiation must occur sequentially to generate accurate movements (Bogacz et al., 2006). Our results apparently contradict these models, and recent data suggest that action preparation and initiation can occur independently (Haith et al., 2016). When choice RT options demand similar movement trajectories, "intermediate" movements between potential targets are often generated at short RTs (Hening et al., 1988). "Prepare-then-move" models interpret intermediate trajectories as errors caused by inadequate preparation. An alternative is that the motor system is efficiently initiating a trajectory that could be adjusted to either target as more data become available or further processing occurs (Hudson et al., 2007; Haith et al., 2016). Our finding that nonspecific initiation units are modulated before action-specific execution units is consistent with the latter interpretation.

In summary, in a choice RT task, Mthal activity is briefly modulated around movement onset, and correlated with the speed of movement initiation and execution. Instead of a strict rate model of BG-thalamocortical function, our results suggest that pulses of Mthal activity modify the kinematics of impending or ongoing movement. This hypothesis makes specific, testable predictions that will allow current models of BG- and cerebellarthalamocortical function to be refined.

\section{References}

Albin RL, Leventhal DK (2017) The missing, the short, and the long: levodopa responses and dopamine actions. Ann Neurol 82:4-19. CrossRef Medline

Albin RL, Young AB, Penney JB (1989) The functional anatomy of basal ganglia disorders. Trends Neurosci 12:366-375. CrossRef Medline

Anderson ME, Turner RS (1991) Activity of neurons in cerebellar-receiving and pallidal-receiving areas of the thalamus of the behaving monkey. J Neurophysiol 66:879-893. CrossRef Medline

Bastian AJ, Kelly VE, Perlmutter JS, Mink JW (2003) Effects of pallidotomy and levodopa on walking and reaching movements in Parkinson's disease. Mov Disord 18:1008-1017. CrossRef Medline

Baunez C, Humby T, Eagle DM, Ryan LJ, Dunnett SB, Robbins TW (2001) Effects of STN lesions on simple vs choice reaction time tasks in the rat: preserved motor readiness, but impaired response selection. Eur J Neurosci 13:1609-1616. CrossRef Medline

Bogacz R, Brown E, Moehlis J, Holmes P, Cohen JD (2006) The physics of optimal decision making: a formal analysis of models of performance in two-alternative forced-choice tasks. Psychol Rev 113:700-765. CrossRef Medline

Bosch-Bouju C, Hyland BI, Parr-Brownlie LC (2013) Motor thalamus integration of cortical, cerebellar and basal ganglia information: implications for normal and parkinsonian conditions. Front Comput Neurosci 7:163. CrossRef Medline

Bosch-Bouju C, Smither RA, Hyland BI, Parr-Brownlie LC (2014) Reduced 
reach-related modulation of motor thalamus neural activity in a rat model of Parkinson's disease. J Neurosci 34:15836-15850. CrossRef Medline

Bostan AC, Dum RP, Strick PL (2010) The basal ganglia communicate with the cerebellum. Proc Natl Acad Sci U S A 107:8452-8456. CrossRef Medline

Boulet S, Lacombe E, Carcenac C, Feuerstein C, Sgambato-Faure V, Poupard A, Savasta M (2006) Subthalamic stimulation-induced forelimb dyskinesias are linked to an increase in glutamate levels in the substantia nigra pars reticulata. J Neurosci 26:10768-10776. CrossRef Medline

Butler EG, Horne MK, Hawkins NJ (1992) The activity of monkey thalamic and motor cortical neurones in a skilled, ballistic movement. J Physiol 445:25-48. CrossRef Medline

Carli M, Evenden JL, Robbins TW (1985) Depletion of unilateral striatal dopamine impairs initiation of contralateral actions and not sensory attention. Nature 313:679-682. CrossRef Medline

Carpenter RH, Williams ML (1995) Neural computation of log likelihood in control of saccadic eye movements. Nature 377:59-62. CrossRef Medline

Chen CH, Fremont R, Arteaga-Bracho EE, Khodakhah K (2014) Short latency cerebellar modulation of the basal ganglia. Nat Neurosci 17:17671775. CrossRef Medline

Chiken S, Nambu A (2016) Mechanism of deep brain stimulation: inhibition, excitation, or disruption? Neuroscientist 22:313-322. CrossRef Medline

Churchland MM, Cunningham JP, Kaufman MT, Ryu SI, Shenoy KV (2010) Cortical preparatory activity: representation of movement or first cog in a dynamical machine? Neuron 68:387-400. CrossRef Medline

Churchland MM, Cunningham JP, Kaufman MT, Foster JD, Nuyujukian P, Ryu SI, Shenoy KV (2012) Neural population dynamics during reaching. Nature 487:51-56. CrossRef Medline

Cif L, Hariz M (2017) Seventy years of pallidotomy for movement disorders. Mov Disord 32:972-982. CrossRef Medline

DeLong MR (1990) Primate models of movement disorders of basal ganglia origin. Trends Neurosci 13:281-285. CrossRef Medline

Deniau JM, Kita H, Kitai ST (1992) Patterns of termination of cerebellar and basal ganglia efferents in the rat thalamus: strictly segregated and partly overlapping projections. Neurosci Lett 144:202-206. CrossRef Medline

Desmurget M, Turner RS (2010) Motor sequences and the basal ganglia: kinematics, not habits. J Neurosci 30:7685-7690. CrossRef Medline

Dowd E, Dunnett SB (2005) Comparison of 6-hydroxydopamine-induced medial forebrain bundle and nigrostriatal terminal lesions in a lateralised nose-poking task in rats. Behav Brain Res 159:153-161. CrossRef Medline

Dudman JT, Krakauer JW (2016) The basal ganglia: from motor commands to the control of vigor. Curr Opin Neurobiol 37:158-166. CrossRef Medline

Ellens DJ, Leventhal DK (2013) Review: electrophysiology of basal ganglia and cortex in models of Parkinson disease. J Parkinsons Dis 3:241-254. CrossRef Medline

Forlano LM, Horne MK, Butler EG, Finkelstein D (1993) Neural activity in the monkey anterior ventrolateral thalamus during trained, ballistic movements. J Neurophysiol 70:2276-2288. CrossRef Medline

Fraser GW, Schwartz AB (2012) Recording from the same neurons chronically in motor cortex. J Neurophysiol 107:1970-1978. CrossRef Medline

Gage GJ, Stoetzner CR, Wiltschko AB, Berke JD (2010) Selective activation of striatal fast-spiking interneurons during choice execution. Neuron 67: 466-479. CrossRef Medline

Galvan A, Devergnas A, Wichmann T (2015) Alterations in neuronal activity in basal ganglia-thalamocortical circuits in the parkinsonian state. Front Neuroanat 9:5. CrossRef Medline

Galvan A, Hu X, Smith Y, Wichmann T (2016) Effects of optogenetic activation of corticothalamic terminals in the motor thalamus of awake monkeys. J Neurosci 36:3519-3530. CrossRef Medline

Guehl D, Pessiglione M, François C, Yelnik J, Hirsch EC, Féger J, Tremblay L (2003) Tremor-related activity of neurons in the "motor" thalamus: changes in firing rate and pattern in the MPTP vervet model of parkinsonism. Eur J Neurosci 17:2388-2400. CrossRef Medline

Guo ZV, Inagaki HK, Daie K, Druckmann S, Gerfen CR, Svoboda K (2017) Maintenance of persistent activity in a frontal thalamocortical loop. Nature 545:181-186. CrossRef Medline

Haith AM, Pakpoor J, Krakauer JW (2016) Independence of movement preparation and movement initiation. J Neurosci 36:3007-3015. CrossRef Medline

Hamid AA, Pettibone JR, Mabrouk OS, Hetrick VL, Schmidt R, Vander Weele CM, Kennedy RT, Aragona BJ, Berke JD (2016) Mesolimbic dopamine signals the value of work. Nat Neurosci 19:117-126. CrossRef Medline

Hashimoto T, Elder CM, Okun MS, Patrick SK, Vitek JL (2003) Stimulation of the subthalamic nucleus changes the firing pattern of pallidal neurons. J Neurosci 23:1916-1923. CrossRef Medline

Heiney SA, Kim J, Augustine GJ, Medina JF (2014) Precise control of movement kinematics by optogenetic inhibition of purkinje cell activity. J Neurosci 34:2321-2330. CrossRef Medline

Hening W, Vicario D, Ghez C (1988) Trajectory control in targeted force impulses: IV. Influences of choice, prior experience and urgency. Exp Brain Res 71:103-115. CrossRef Medline

Horak FB, Anderson ME (1984a) Influence of globus pallidus on arm movements in monkeys: I. Effects of kainic acid-induced lesions. J Neurophysiol 52:290-304. CrossRef Medline

Horak FB, Anderson ME (1984b) Influence of globus pallidus on arm movements in monkeys: II. Effects of stimulation. J Neurophysiol 52:305322. CrossRef Medline

Hudson TE, Maloney LT, Landy MS (2007) Movement planning with probabilistic target information. J Neurophysiol 98:3034-3046. CrossRef Medline

Jin X, Tecuapetla F, Costa RM (2014) Basal ganglia subcircuits distinctively encode the parsing and concatenation of action sequences. Nat Neurosci 17:423-430. CrossRef Medline

Kaufman MT, Seely JS, Sussillo D, Ryu SI, Shenoy KV, Churchland MM (2016) The largest response component in the motor cortex reflects movement timing but not movement type. eNeuro 3:ENEURO.008516.2016. CrossRef Medline

Kim J, Kim Y, Nakajima R, Shin A, Jeong M, Park AH, Jeong Y, Jo S, Yang S, Park H, Cho SH, Cho KH, Shim I, Chung JH, Paik SB, Augustine GJ, Kim D (2017) Inhibitory basal ganglia inputs induce excitatory motor signals in the thalamus. Neuron 95:1181-1196.e8. CrossRef Medline

Kravitz AV, Freeze BS, Parker PR, Kay K, Thwin MT, Deisseroth K, Kreitzer AC (2010) Regulation of parkinsonian motor behaviours by optogenetic control of basal ganglia circuitry. Nature 466:622-626. CrossRef Medline

Kuramoto E, Fujiyama F, Nakamura KC, Tanaka Y, Hioki H, Kaneko T (2011) Complementary distribution of glutamatergic cerebellar and GABAergic basal ganglia afferents to the rat motor thalamic nuclei. Eur J Neurosci 33:95-109. CrossRef Medline

Lauwereyns J, Watanabe K, Coe B, Hikosaka O (2002) A neural correlate of response bias in monkey caudate nucleus. Nature 418:413-417. CrossRef Medline

Lee KH, Mathews PJ, Reeves AM, Choe KY, Jami SA, Serrano RE, Otis TS (2015) Circuit mechanisms underlying motor memory formation in the cerebellum. Neuron 86:529-540. CrossRef Medline

Leventhal DK, Gage GJ, Schmidt R, Pettibone JR, Case AC, Berke JD (2012) Basal ganglia beta oscillations accompany cue utilization. Neuron 73:523536. CrossRef Medline

Leventhal DK, Stoetzner C, Abraham R, Pettibone J, DeMarco K, Berke JD (2014) Dissociable effects of dopamine on learning and performance within sensorimotor striatum. Basal Ganglia 4:43-54. CrossRef Medline

Macpherson JM, Rasmusson DD, Murphy JT (1980) Activities of neurons in "motor" thalamus during control of limb movement in the primate. J Neurophysiol 44:11-28. CrossRef Medline

Magnin M, Morel A, Jeanmonod D (2000) Single-unit analysis of the pallidum, thalamus and subthalamic nucleus in parkinsonian patients. Neuroscience 96:549-564. CrossRef Medline

Maia TV, Frank MJ (2011) From reinforcement learning models to psychiatric and neurological disorders. Nat Neurosci 14:154-162. CrossRef Medline

Marsden CD, Obeso JA (1994) The functions of the basal ganglia and the paradox of stereotaxic surgery in Parkinson's disease. Brain 117:877-897. CrossRef Medline

McIntyre CC, Grill WM, Sherman DL, Thakor NV (2004) Cellular effects of deep brain stimulation: model-based analysis of activation and inhibition. J Neurophysiol 91:1457-1469. CrossRef Medline

Meyer-Lohmann J, Hore J, Brooks VB (1977) Cerebellar participation in 
generation of prompt arm movements. J Neurophysiol 40:1038-1050. CrossRef Medline

Mink JW, Thach WT (1991) Basal ganglia motor control. II. Late pallidal timing relative to movement onset and inconsistent pallidal coding of movement parameters. J Neurophysiol 65:301-329. CrossRef Medline

Molnar GF, Pilliar A, Lozano AM, Dostrovsky JO (2005) Differences in neuronal firing rates in pallidal and cerebellar receiving areas of thalamus in patients with Parkinson's disease, essential tremor, and pain. J Neurophysiol 93:3094-3101. CrossRef Medline

Nakamura KC, Sharott A, Magill PJ (2014) Temporal coupling with cortex distinguishes spontaneous neuronal activities in identified basal gangliarecipient and cerebellar-recipient zones of the motor thalamus. Cereb Cortex 24:81-97. CrossRef Medline

Nambu A, Yoshida S, Jinnai K (1991) Movement-related activity of thalamic neurons with input from the globus pallidus and projection to the motor cortex in the monkey. Exp Brain Res 84:279-284. Medline

Niv Y, Daw ND, Joel D, Dayan P (2007) Tonic dopamine: opportunity costs and the control of response vigor. Psychopharmacology (Berl) 191:507520. CrossRef Medline

Noorani I, Carpenter RH (2011) Full reaction time distributions reveal the complexity of neural decision-making. Eur J Neurosci 33:1948-1951. CrossRef Medline

Ohmae S, Kunimatsu J, Tanaka M (2017) Cerebellar roles in self-timing for sub- and supra-second intervals. J Neurosci 37:3511-3522. CrossRef Medline

Panigrahi B, Martin KA, Li Y, Graves AR, Vollmer A, Olson L, Mensh BD, Karpova AY, Dudman JT (2015) Dopamine is required for the neural representation and control of movement vigor. Cell 162:1418-1430. CrossRef Medline

Paxinos G, Watson C (2007) The rat brain in stereotaxic coordinates. Amsterdam, the Netherlands: Elsevier.

Pessiglione M, Guehl D, Rolland AS, François C, Hirsch EC, Féger J, Tremblay L (2005) Thalamic neuronal activity in dopamine-depleted primates: evidence for a loss of functional segregation within basal ganglia circuits. J Neurosci 25:1523-1531. CrossRef Medline

Pullman SL, Watts RL, Juncos JL, Chase TN, Sanes JN (1988) Dopaminergic effects on simple and choice reaction time performance in Parkinson's disease. Neurology 38:249-254. CrossRef Medline

Redgrave P, Vautrelle N, Reynolds JN (2011) Functional properties of the basal ganglia's re-entrant loop architecture: selection and reinforcement. Neuroscience 198:138-151. CrossRef Medline

Rovó Z, Ulbert I, Acsády L (2012) Drivers of the primate thalamus. J Neurosci 32:17894-17908. CrossRef Medline

Rubin JE, McIntyre CC, Turner RS, Wichmann T (2012) Basal ganglia activity patterns in parkinsonism and computational modeling of their downstream effects. Eur J Neurosci 36:2213-2228. CrossRef Medline
Schmidt R, Leventhal DK, Mallet N, Chen F, Berke JD (2013) Canceling actions involves a race between basal ganglia pathways. Nat Neurosci 16:1118-1124. CrossRef Medline

Summerside EM, Shadmehr R, Ahmed AA (2018) Vigor of reaching movements: reward discounts the cost of effort. J Neurophysiol 119:2347-2357. CrossRef Medline

Tanaka M (2005) Involvement of the central thalamus in the control of smooth pursuit eye movements. J Neurosci 25:5866-5876. CrossRef Medline

Tanaka M (2007) Cognitive signals in the primate motor thalamus predict saccade timing. J Neurosci 27:12109-12118. CrossRef Medline

Teune TM, van der Burg, van der Moer J, Voogd J, Ruigrok TJ (2000) Topography of cerebellar nuclear projections to the brain stem in the rat. Prog Brain Res 124: 141-72. CrossRef Medline

Thach WT (1975) Timing of activity in cerebellar dentate nucleus and cerebral motor cortex during prompt volitional movement. Brain Res 88:233-241. CrossRef Medline

Thorn CA, Atallah H, Howe M, Graybiel AM (2010) Differential dynamics of activity changes in dorsolateral and dorsomedial striatal loops during learning. Neuron 66:781-795. CrossRef Medline

Thura D, Cisek P (2017) The basal ganglia do not select reach targets but control the urgency of commitment. Neuron 95:1160-1170.e5. CrossRef Medline

Trouche E, Beaubaton D (1980) Initiation of a goal-directed movement in the monkey: role of the cerebellar dentate nucleus. Exp Brain Res 40:311321. Medline

van Donkelaar P, Stein JF, Passingham RE, Miall RC (1999) Neuronal activity in the primate motor thalamus during visually triggered and internally generated limb movements. J Neurophysiol 82:934-945. CrossRef Medline

Xiao Y, Agnesi F, Bello EM, Zhang S, Vitek JL, Johnson MD (2018) Deep brain stimulation induces sparse distributions of locally modulated neuronal activity. Sci Rep 8:2062. CrossRef Medline

Yamamoto S, Monosov IE, Yasuda M, Hikosaka O (2012) What and where information in the caudate tail guides saccades to visual objects. J Neurosci 32:11005-11016. CrossRef Medline

Yamawaki N, Shepherd GM (2015) Synaptic circuit organization of motor corticothalamic neurons. J Neurosci 35:2293-2307. CrossRef Medline

Yttri EA, Dudman JT (2016) Opponent and bidirectional control of movement velocity in the basal ganglia. Nature 533:402-406. CrossRef Medline

Yttri EA, Dudman JT (2018) A proposed circuit computation in basal ganglia: history-dependent gain. Mov Disord 33:704-716. CrossRef Medline

Zirh TA, Lenz FA, Reich SG, Dougherty PM (1998) Patterns of bursting occurring in thalamic cells during parkinsonian tremor. Neuroscience 83:107-121. CrossRef Medline 